ISSN 1112-9867

http://www.jfas.info

\title{
EXPERIMENTAL STUDY OF MILLING TITANIUM ALLOY (TI-6A1-4V) FOR DEFENCE APPLICATION
}

\author{
R. Izamshah*, B. I. Redzuwan, M. S. A. Aziz, M. S. Kasim and M. Hadzley \\ Precision Machining Group, Advanced Manufacturing Centre, Faculty of Manufacturing \\ Engineering, Universiti Teknikal Malaysia Melaka, Malaysia
}

Published online: 10 September 2017

\begin{abstract}
Due to its high strength-to-weight ratio in which $40 \%$ lighter and closely matching the mechanical properties of steel, titanium alloy being used in military applications to reduced weight and increase durability in extreme conditions for improving the mobility and combat effectiveness. Titanium alloy are categorized as a difficult-to-cut material which have low machinability ratings. Problems in machining titanium alloy are mainly due to the high cutting temperatures, low modulus of elasticity of the material and chemical reactions with the tools. In order to improve titanium machining, selection of cutting tools with good machinability is very important. For manufacturers, selection of the best cutting tool types that can meets the machining performances i.e. fine surface roughness and high tool life alligned with the tool cost are necessitate in order to sustain in the competitive defence and military sector.
\end{abstract}

Keywords: surface roughness; titanium alloy (Ti-6Al-4V); TiAlN/AlCrN PVD/CVD coated; tungsten carbide insert.

Author Correspondence, e-mail: izamshah@utem.edu.my

doi: http://dx.doi.org/10.4314/jfas.v9i3s.21 


\section{INTRODUCTION}

The increased knowledge of titanium alloy intrisic properties and its capabilities brought a shift in the defense and military applications. Due to its high strength-to-weight ratio in which $40 \%$ lighter and closely matching the mechanical properties of steel, titanium alloy being used in military applications to reduced weight and increase durability in extreme conditions for improving the mobility and combat effectiveness [1]. Table 1 depicted the example of weight reduction for titanium material application in military vehicle. In addition, this material also exhibit overall superior corrosion resistance and exceptional elevated temperature performance. In defence applications, titanium alloy area are widely used in the applications of armor plating for protection against ballistic threat, missiles warhead casing and aircraft structure and engine component. Fig. 1-3 show the application of titanium alloy in defence and military sector.

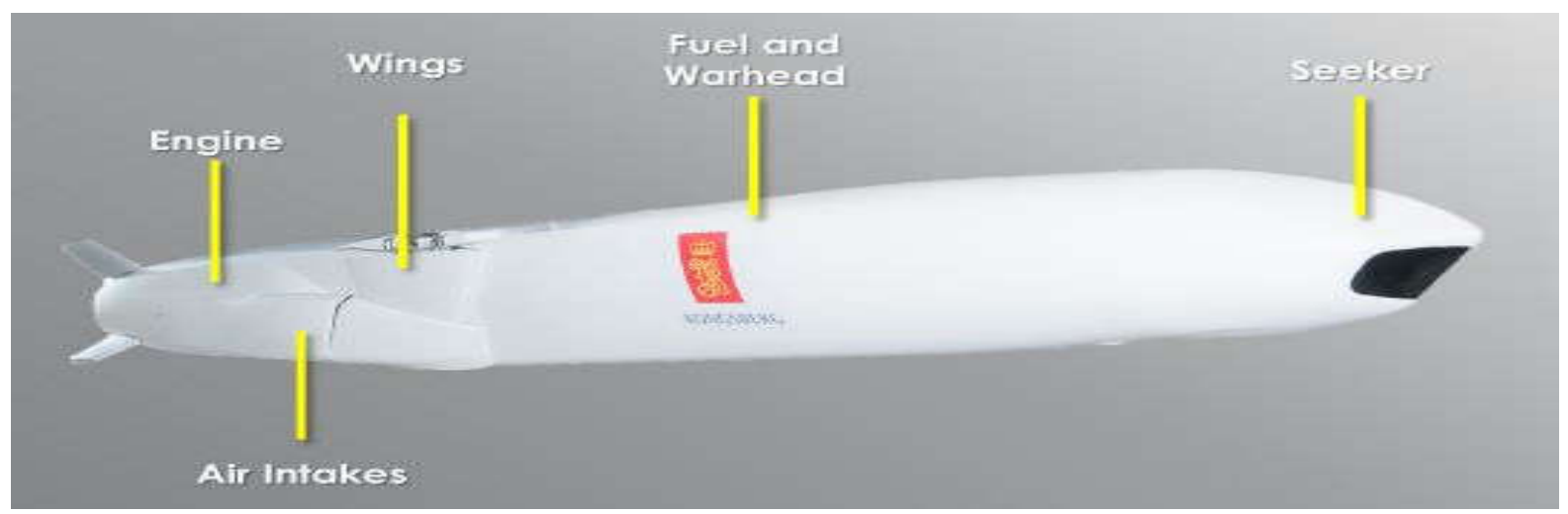

Fig.1. Titanium alloy naval strike missile warhead casing [2]

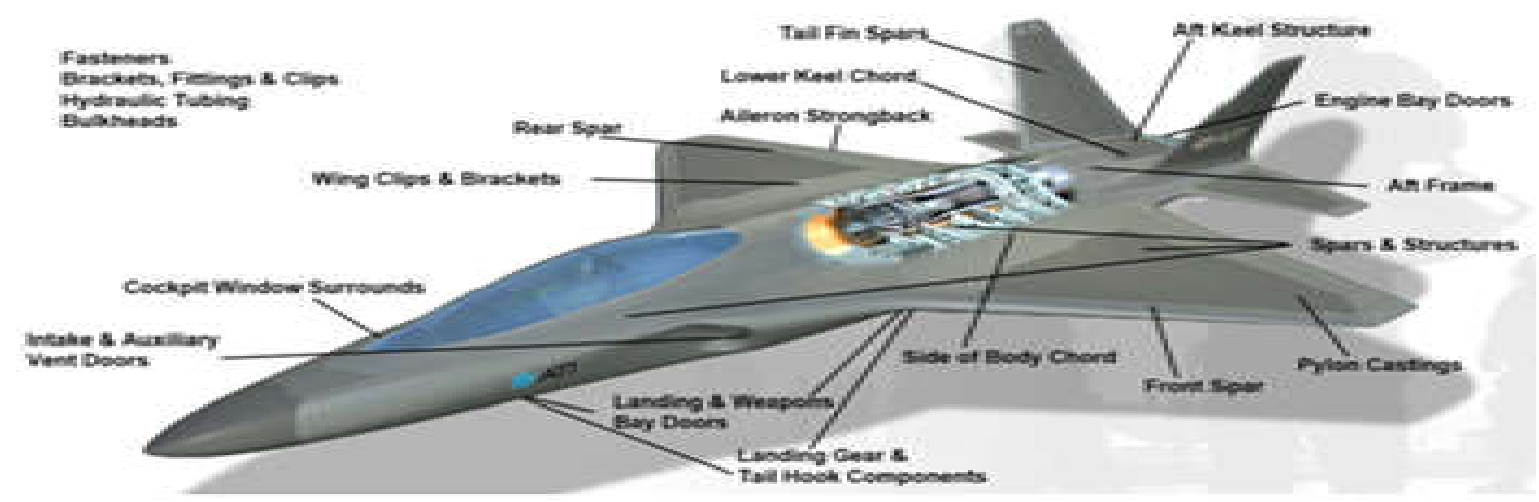

Fig.2. Military airframe application using titanium alloy [3] 


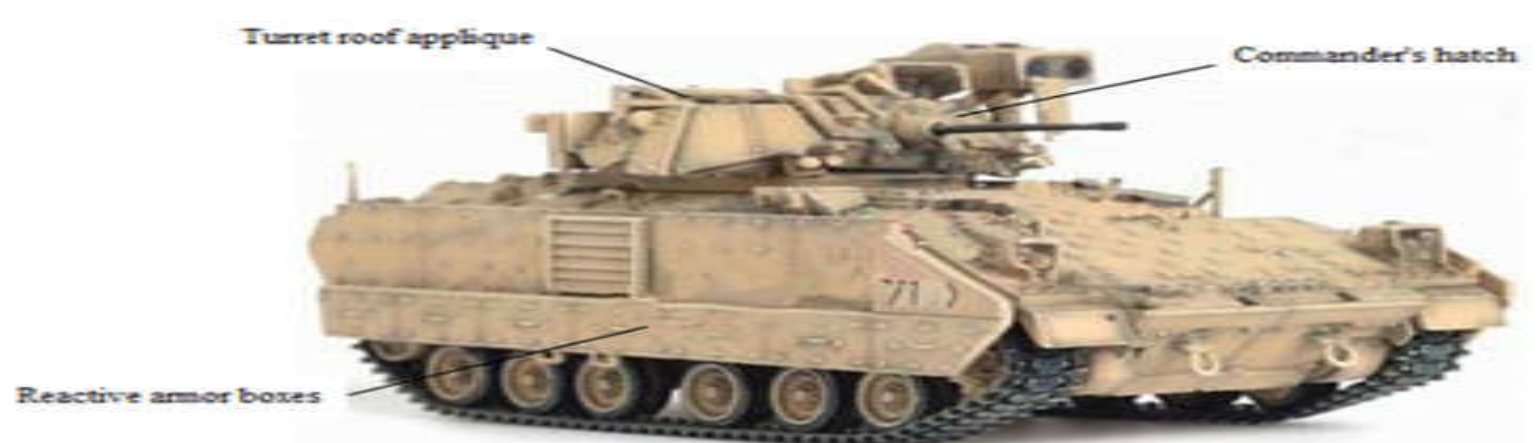

Fig.3. Land defence applications examples of titanium uses [3]

Titanium alloy are categorized as a difficult-to-cut material due to their high chemical reactivity, high temperature, high strength, low thermal conductivity and relatively low modulus of elasticity which have low machinability ratings [4-7]. Generally, for most of the military applications the components are either forged or cast to the approximate final shape and the milling process was used to finish machine the parts or the component was machined from a solid block of material by milling with roughing and finishing cuts [8]. However, the superior properties of titanium alloy create several manufacturing challenges which impact on the total production costs.

Table 1. Weight reduction for titanium material application in Abram M1A2 battle tank (ATI) [9]

\begin{tabular}{ccccc}
\hline Replacement Components & \multicolumn{2}{c}{ Weight (kg) } & \multicolumn{2}{c}{ Weight Saved } \\
& RHA Steel & Titanium & (kg) & (\%) \\
\hline Turret blow-off panels & 311 & 229 & 82 & 26 \\
Gunner's primary sight GPS cover & 227 & 160 & 67 & 30 \\
NBC cover & 168 & 132 & 36 & 21 \\
Engine top cover & 498 & 358 & 140 & 28 \\
Turre pivot rack & 160 & 90 & 70 & 44 \\
Commander's hatch & 80 & 56 & 24 & 30 \\
Commander's independent thermal viewer & 146 & 92 & 54 & 37 \\
Total & 1590 & 1117 & 473 & 30 \\
\hline
\end{tabular}

Problems in machining titanium alloy are mainly due to the high cutting temperatures, low modulus of elasticity of the material and chemical reactions with the tools. Unlike steel, 
titanium alloy does not form a built-up edge on the tools which increases the abrading and alloying action of the thin chip forcing over a small tool-chip contact area under high pressure [10]. Both combination phenomena and the relatively poor thermal conductivity of titanium results in unusually high tool-tip temperatures. Relatively, the strong chemical reactivity of titanium with tool materials at high cutting temperatures and pressures causes galling, welding and smearing along with rapid destruction of the cutting tool. In addition, the low elastic modulus coupled with high thrust forces required at the cutting edge can cause deflection in slender parts. Due to the distortion, additional heat is developed that can affect the part tolerances. Although there were several works found in the literatures that dealt with machining titanium alloy material, most of the presented results only concentrate on tool performance rather than surface finish. Surface finish has a major effect on the integrity and the adequate functioning of the parts and should be methodically investigate which will be the matter to be studied in this paper.

For manufacturers, selection of the best cutting tool types that can meets the machining performances i.e. fine surface roughness and high tool life alligned with the tool cost are necessitate in order to sustain in the competitive defence and military sector. In addition, the selection of best cutting tool process are complicated as both of the coating processes and coating materials must be taken into consideration that need to be experimentally tested.

\section{EXPERIMENTAL}

\subsection{Workpiece}

The material used as the workpiece in this research is titanium alloy (Ti-6Al-4V). The details composition and the mechanical properties of this material are shown in Table 2 respectively. A titanium alloy block with the size of $120 \times 100 \times 50 \mathrm{~mm}$ was used throughout this experiment as shown in Fig. 4. The worpiece surface was skimmed down to $0.5 \mathrm{~mm}$ to remove any surface alteration or defects from the previous manufacturing process [12]. 


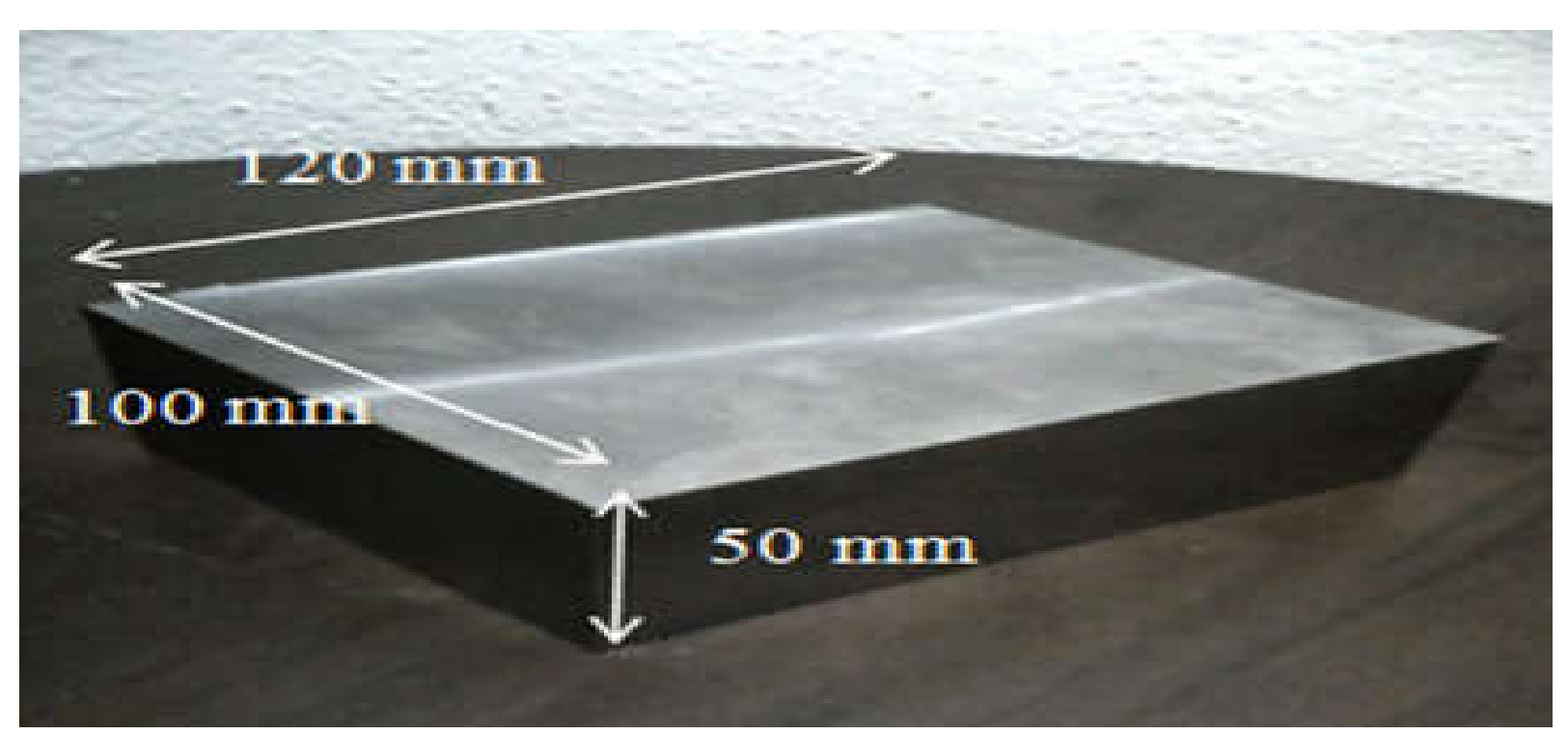

Fig.4. Titanium alloy Ti-6Al-4V block with dimension

Table 2. The composition (wt\%) and mechanical properties of titanium alloy [7]

\begin{tabular}{cccccccc}
\hline Content & $\mathbf{H}$ & $\mathbf{N}$ & $\mathbf{C}$ & $\mathbf{F e}$ & $\mathbf{V}$ & $\mathbf{A l}$ & $\mathbf{T i}$ \\
\hline $\mathbf{W t} \%$ & 0.005 & 0.01 & 0.05 & 0.09 & 4.40 & 6.15 & Balance \\
\hline
\end{tabular}

\begin{tabular}{ccccc}
\hline $\begin{array}{c}\text { Tensile } \\
\text { Strength (MPa) }\end{array}$ & $\begin{array}{c}\text { Yield } \\
\text { Strength (MPa) }\end{array}$ & $\begin{array}{c}\text { Density } \\
\left(\mathbf{k g} / \mathbf{m}^{\mathbf{3}}\right)\end{array}$ & $\begin{array}{c}\text { Modulus of } \\
\text { Elasticity (GPa) }\end{array}$ & $\begin{array}{c}\text { Hardness } \\
\text { (HRC) }\end{array}$ \\
\hline 993 & 830 & 4540 & 114 & 36 \\
\hline
\end{tabular}

\subsection{Machining Condition}

Two types of round shape tungsten carbide insert were used in these experiments which were PVD coated insert and CVD coated insert as shown in Fig. 5. The machining conditions for the experiment are described in Table 3.
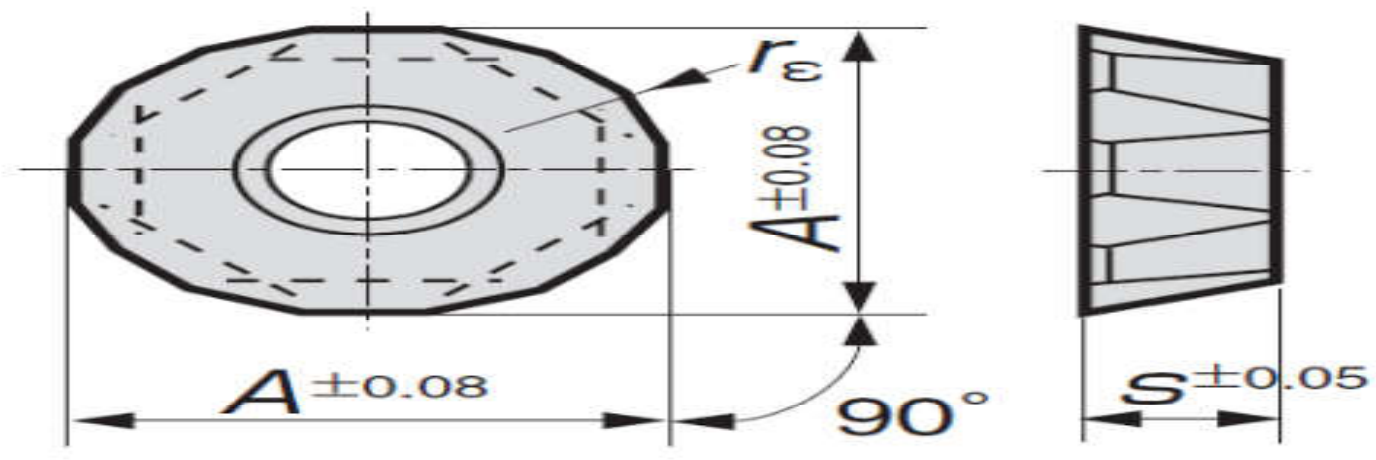

Fig.5. Schematic geometry of PVD and CVD insert 
Table 3. Machining condition for the experiment

\begin{tabular}{ccc}
\hline Type of Tool & \multicolumn{2}{c}{ Round Shape of PVD Coated Insert and CVD Coated } \\
Insert & \\
\hline Dimensional & Insert diameter, A & $10 \mathrm{~mm}$ \\
Geometry of Tool & Nose radius, rs & $3.5 \mathrm{~mm}$ \\
Machine & Thickness, S & $3.97 \mathrm{~mm}$ \\
Atmosphere & Mazak CNC milling machine \\
\hline
\end{tabular}

A Response Surface Methodology (RSM) using Box Behken data approach was employed in order to determine the optimum parameter. The parameter range setting was considered based on the tool maker recommendation and setting from the previous studies as shown in Table 4.

Table 4. Specification of cutting parameter

\begin{tabular}{ccc}
\hline Control Parameter & \multicolumn{3}{c}{ Parameter Range } \\
\hline Level & -1 & 1 \\
Cutting speed, $V_{c}(\mathrm{~m} / \mathrm{min})$ & 120 & 180 \\
Feed rate, $f_{z}(\mathrm{~mm} /$ tooth $)$ & 0.1 & 0.2 \\
Depth of cut, $D o C(\mathrm{~mm})$ & 0.1 & 0.5 \\
\hline
\end{tabular}

\section{RESULTS AND DISCUSSION}

In this study, analysis on independent machining variables that includes cutting speed, feed rate, depth of cut and tool type was performed in order to response to the surface roughness of PVD and CVD coated tungsten carbide inserts on titanium alloy The average surface roughness was determined through the constant trend of each experiment, where the constant trend occurs at different machining times. The experiments result for both CVD and PVD coated inserts are shown in Table 5 respectively. 
Table 5. Average surface roughness of PVD and CVD insert tool

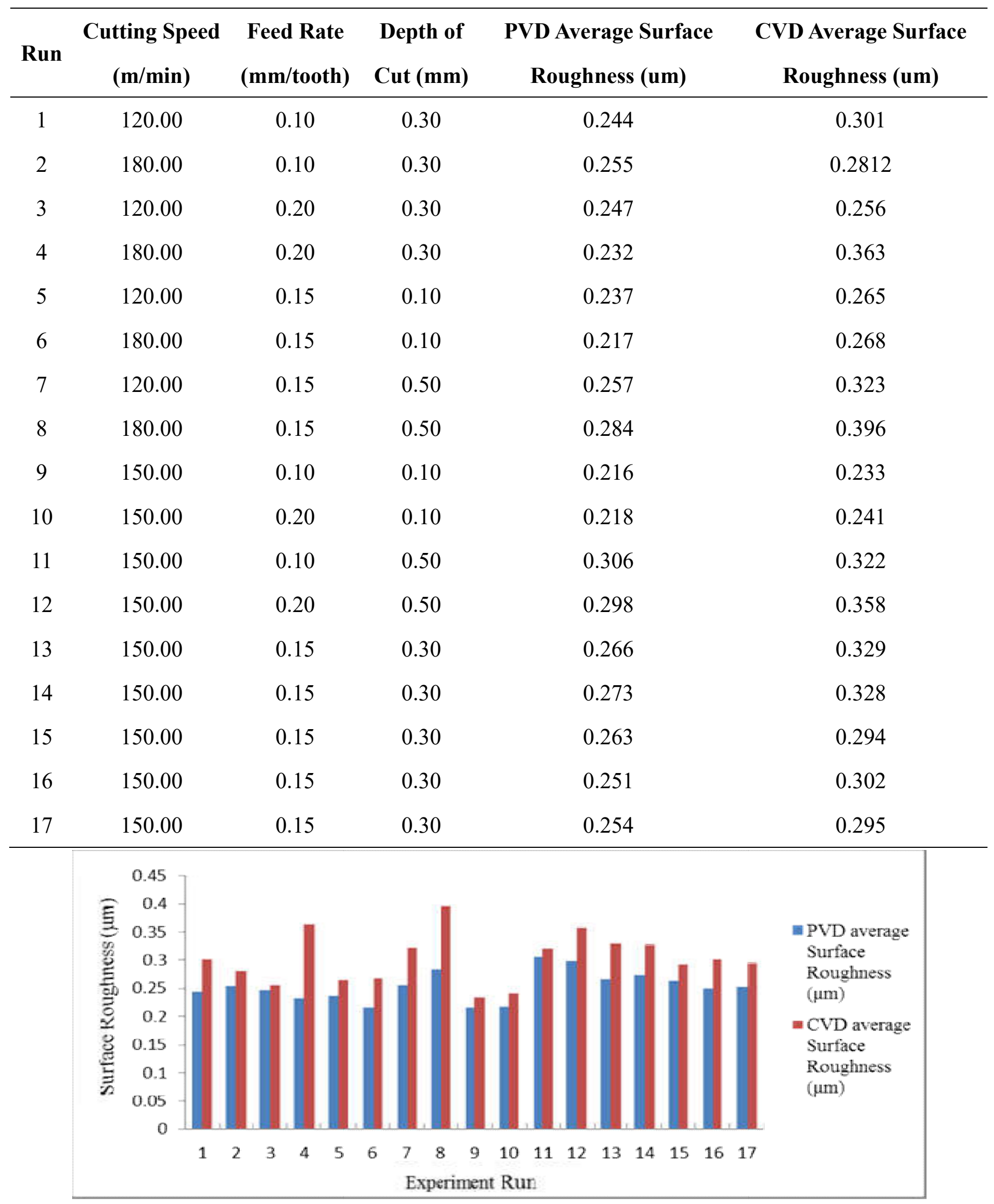

Fig.6. Average surface roughness results between PVD and CVD insert tool 


\subsection{Average Surface Roughness over Cutting Speed}

Based on Fig. 7, it can be observed that the values of surface roughness produced from all of the conditions varied between 0.217 and $0.396 \mu \mathrm{m}$. Notably, for PVD tool the lowest surface roughness value was obtained at the highest cutting speed i.e. $180 \mathrm{~m} / \mathrm{min}$. Contrary, the lowest surface roughness value obtained from CVD tool was at the lowest cutting speed i.e. 120 $\mathrm{m} / \mathrm{min}$. In addition, the highest values of surface roughness for PVD and CVD tool were at moderate cutting speed i.e. $150 \mathrm{~m} / \mathrm{min}$ and at the highest cutting speed i.e. $180 \mathrm{~m} / \mathrm{min}$ respectively. One of the possible reason of this phenomena are due to the coating adhesion between PVD and CVD types that affect the friction and contact between cutting tool and workpiece surface towards the cutting condition i.e. cutting speed [11-12]. From the results, it shows that in machining titanium alloy material; different tool type requires its own set of optimum combination of machining parameters in order to obtain a good surface finish.

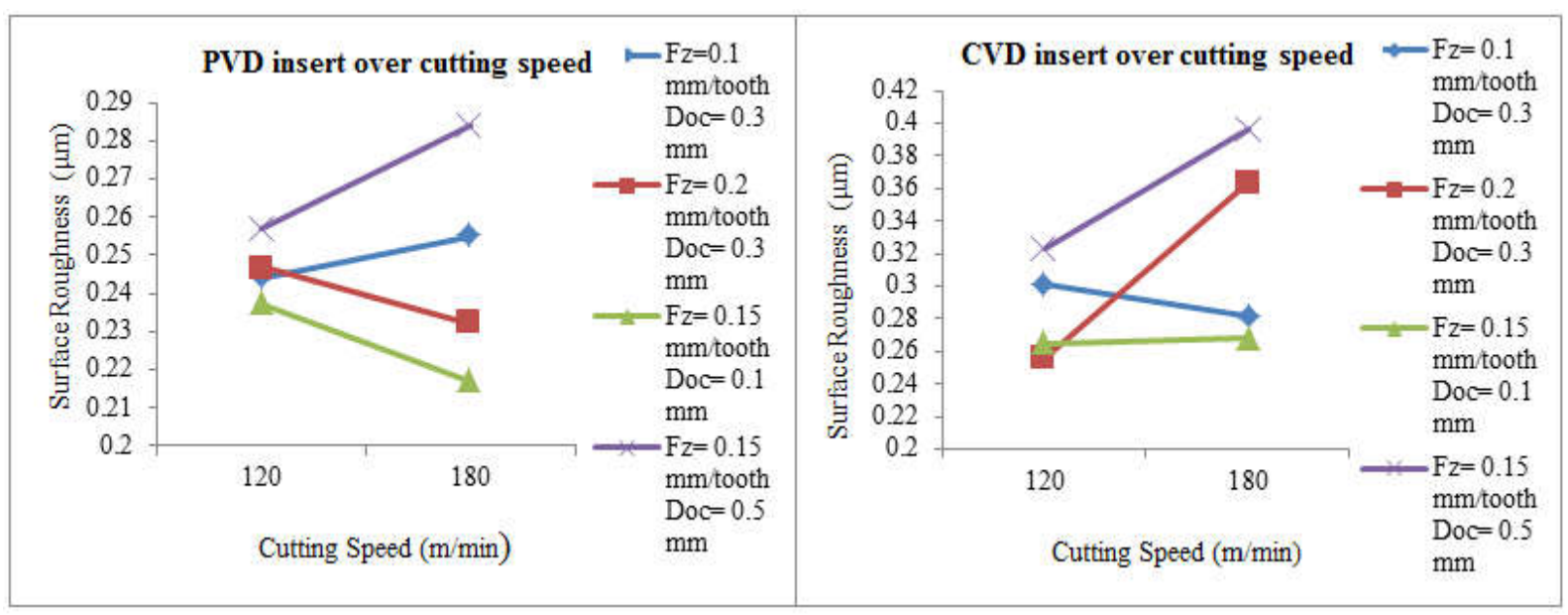

Fig.7. Average surface roughness of PVD and CVD insert over cutting speed

\subsection{Average Surface Roughness over Feed Rate}

Fig. 8 shows the differences of average surface roughness result occurred at 0.1 and 0.2 $\mathrm{mm} /$ tooth of feed rate. It can be observed that the values of surface roughness produced from all of the conditions varied between 0.216 and $0.396 \mu \mathrm{m}$. Although the average surface roughness increased along with the increase of feed rate on CVD insert, but on PVD insert the feed rate has less effect on the average surface roughness. It was spotted especially for PVD insert at $\mathrm{Vc}=180 \mathrm{~m} / \mathrm{min}$ with $\mathrm{DoC}=0.3 \mathrm{~mm}$ and $\mathrm{Vc}=150 \mathrm{~m} / \mathrm{min}$ with $\mathrm{DoC}=0.5 \mathrm{~mm}$. One of the possible reason of this phenomena are due higher cutting speed at $150 \mathrm{~m} / \mathrm{min}$ and 180 
$\mathrm{m} / \mathrm{min}$. Small range value of feed rate between 0.1 and $0.2 \mathrm{~mm} /$ tooth also one of the possible reason that causing the obtained results. Furthermore, it shows that the feed rate has more effect on CVD insert where the increase of feed rate results in higher surface roughness i.e. Fz $=0.2 \mathrm{~mm} /$ tooth results 0.363 and $0.358 \mu \mathrm{m}$. The surface roughness value proportionally increased with the increment of feed rate as shown by [13]. In other words, the larger the feed rate the higher the value of surface roughness due to the higher vibration, forces and temperature occurs at higher cutting depth, which led to higher surface roughness [14-15].

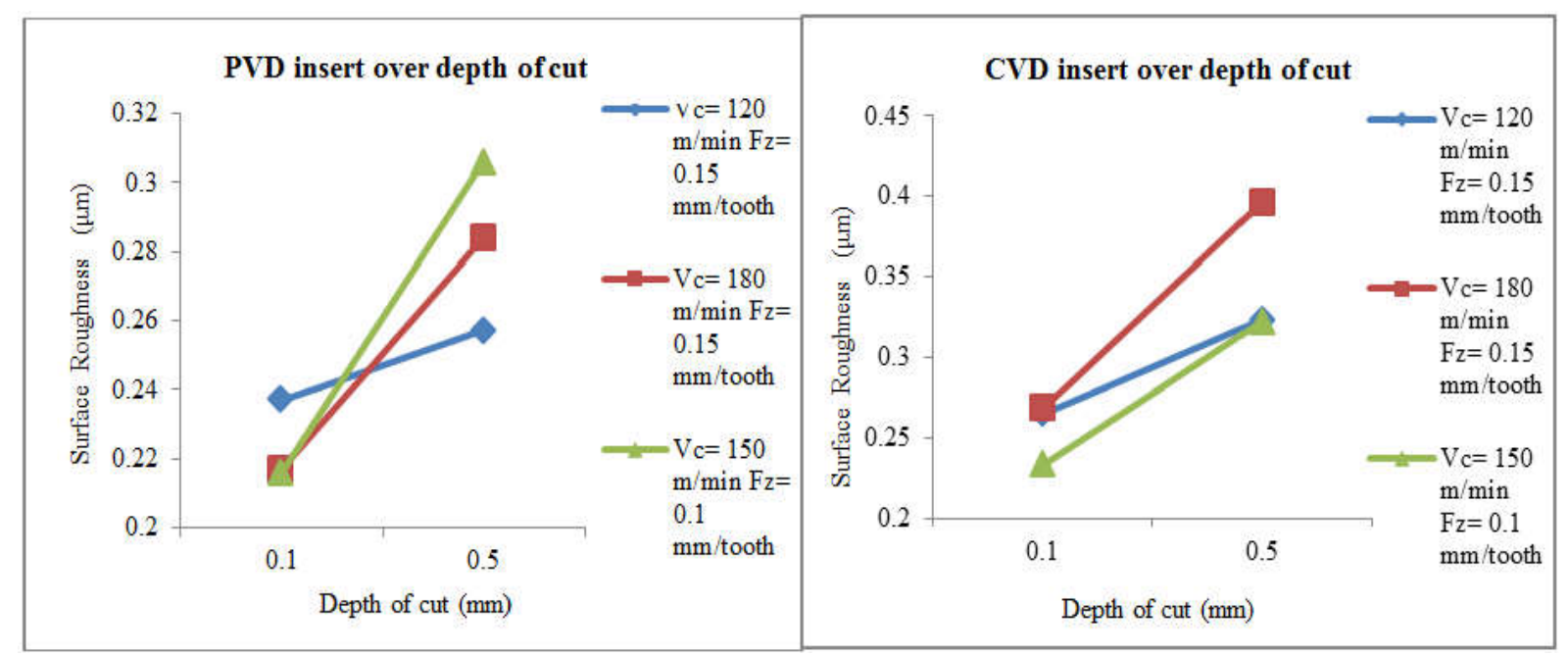

Fig.8. Average surface roughness of PVD and CVD insert over feed rate

\subsection{Average Surface Roughness over Depth of Cut}

Based on Fig. 9, the lowest average surface roughness of $0.216 \mu \mathrm{m}$ was achieved at DoC $=$ $0.1 \mathrm{~mm}$ while the highest average surface roughness of $0.396 \mu \mathrm{m}$ obtained at DoC $=0.5 \mathrm{~mm}$. It can be observed that PVD insert produced the lowest surface finish with $0.216 \mu \mathrm{m}$ compare to CVD insert with surface finish $0.233 \mu \mathrm{m}$ at $\mathrm{Vc}=150 \mathrm{~m} / \mathrm{min}, \mathrm{Fz}=0.1 \mathrm{~mm} /$ tooth and $\mathrm{DoC}=$ $0.1 \mathrm{~mm}$. It proved that the need to reduce the depth of cut as a function of surface roughness are explained by the fact that as the depth of cut increases, the cutting forces increase. Therefore, deformation of the workpiece and the tool increase that promotes the chatter occurrence. 


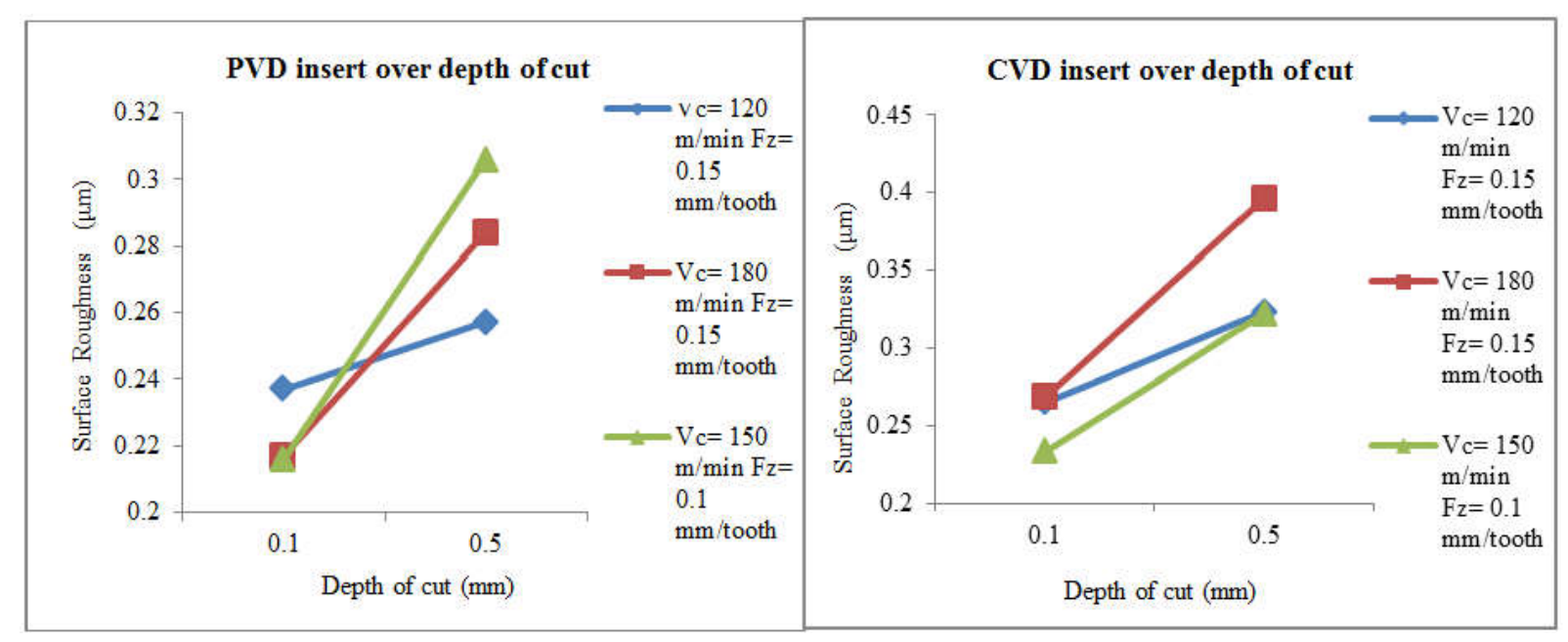

Fig.9. Average surface roughness of PVD and CVD insert over depth of cut

\section{CONCLUSION}

The following conclusions are mainly based on the objectives along with the results and discussions for the experimental of milling titanium alloy Ti-6Al-4V using PVD and CVD carbide insert under dry condition. From the conducted investigation, it shows that PVD coated tool produced better surface finished than CVD coated tool where PVD coated tools have been found to be better performing compared to their CVD counterparts. Also, in PVD thinner coatings can be deposited and sharp edges and complex shapes can be easily coated at lower temperatures. PVD insert are used frequently in metal cutting process due to their high hardness, wear resistance and chemical stability. Also, they offer higher benefits in terms of tool life and machining performance compared to other coated cutting tool variants. The geometry of the cutting tool used in this experiment also obtained the low value of surface roughness. The round shape of PVD and CVD insert can be considered as large nose radius where the higher the nose radius result the lower value of the surface roughness. The surface roughness also depends on the machine tool rigidity and the geometry of the cutting tool.

Also, the vibration or chatter occurred during the machining process also can give significant impact on the surface finish. Selection of cutting parameters is very crucial in order to avoid chatter. Besides that, the experiment result also shows that cutting condition of higher cutting speed, feed rate and depth of cut promotes a good surface roughness. A better surface finish was achieved at high cutting speed, $\mathrm{Vc}=150 \mathrm{~m} / \mathrm{min}$, low feed rate, $\mathrm{Fz}=0.1 \mathrm{~mm} /$ tooth and 
depth of cut, DoC $=0.1 \mathrm{~mm}$, where it produces low average surface roughness of $0.216 \mu \mathrm{m}$ for PVD insert and $0.233 \mu \mathrm{m}$. Therefore, the experiment shows that the higher value of depth of cut, result the higher value of surface roughness for both type of insert which is PVD and CVD insert. This means machining parameters which are cutting speed, feed rate and surface roughness are significant in affecting the results of surface roughness.

\section{ACKNOWLEDGEMENTS}

The authors would like to express our gratitude to the Universiti Teknikal Malaysia Melaka (UTeM) for experimental facilities used in this project and MyBrain scholarship. This research is supported under Short Term Research Grant Scheme no. PJP/2013/FKP(15B)/S01219.

\section{REFERENCES}

[1] William A, Gooch Jr. Potential application of titanium alloys in armor systems. California: International Titanium Association, 2011

[2] Kongsberg. Naval strike missile-NSM. Buskerud: Kongsberg, 2014

[3] Daad M, Omran H, Ra'Ed K. Applying the image of titanium-made medical and military products in political posters for achieving security and world peace. International Journal of Graphics and Multimedia, 2016, 7(1):1-13

[4] Veiga C, Davim J P, Loureiro A J R. Review on machinability of titanium alloys: The process perspective. Review on Advance Material Science, 2013, 34:148-164

[5] Izamshah R A R, John P T M, Songlin D. Finite element analysis of machining thin-wall parts. Journal Key Engineering Materials, 2011, 458:283-288

[6] Izamshah R, Husna N, Hadzley M, Amran M, Shahir M. Effects of cutter geometrical feature on machining polyetheretherketone (PEEK) engineering plastic. In 2nd International Conference on Mechanical Engineering Research, 2012, pp. 863-872

[7] Mohd H A B, Izamshah R, Siti S A, Nurul F M. Finite element model of machining with high pressure coolant for Ti-6Al-4V alloy. Procedia Engineering, 2013, 53:624-631

[8] Rammohan S, Rama R. Cutting strategies for casting die manufacturing on CNC milling 
machine. IOSR Journal of Mechanical and Civil Engineering, 2013, 7(4):15-23

[9] Richard J H. Military airframe, land and sea based application for titanium. 2012, http://c.ymcdn.com/sites/www.titanium.org/resource/resmgr/2010_2014_papers/HarshmanRic hard2012.pdf

[10] Songlin D, Izamshah R A R, John P T M, Yongwei Z. Chatter detection in high speed machining of titanium alloys. Key Engineering Materials, 2011, 458:289-294

[11] Jaharah A G, Che Hassan C H. Failure mode analysis of carbide cutting tools used for machining titanium alloy. Ceramics International, 2012, 39(4):4449-4456.

[12] Mehta N. K. Metal cutting and design of cutting tools, jigs and fixtures. New Delhi: McGraw Hill Education, 2015

[13] Davim J. P. Machining of titanium alloys. Berlin: Springer, 2014

[14] Nouari M, Ginting A. Wear characteristics and performance of multi-layer CVD-coated alloyed carbide tool in dry end milling of titanium alloy. Surface and Coatings Technology, 2006, 200(18):5663-5676

[15] Kasim M S, Haron C H C, Ghani J A, Sulaiman M A. Prediction surface roughness in high-speed milling of Inconel 718 under MQL using RSM method. Middle-East Journal of Science Research, 2013, 13(3):264-272

\section{How to cite this article:}

Izamshah R, Redzuwan BI, Aziz MSA, Kasim MS, Hadzley M. Experimental study of milling titanium alloy (ti-6a1-4v) for defence application. J. Fundam. Appl. Sci., 2017, 9(3S), $245-256$. 